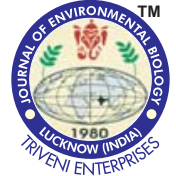

G

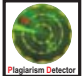

DOI: https://doi.org/10.22438/jeb/38/3/MRN-452

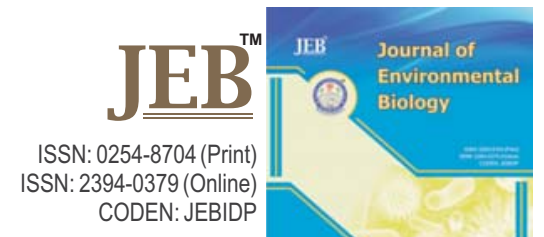

\title{
Effect of polyherbal extract on TCA cycle enzymes and heart tissue histology in isoproterenol induced myocardial rats
}

Authors Info

\section{B. Ragavan* and S. Monisha}

Department of Biochemistry, PSG college of Arts and Science, Coimbatore-641 014, India

${ }^{*}$ Corresponding Author Email : moni1487@gmail.com

\section{Key words}

Histopathology,

Myocardial infarction,

Polyherbal crude extract,

TCA cycle enzymes

Publication Info

Paper received : 08.09.2016

Revised received : 16.11 .2016

Re-revised received : 11.01.2017

Accepted: 19.01.2017

\section{Abstract}

Aim: Cardiovascular disease has become a universal cause of morbidity and largely contributes to mortality in developed and developing countries. The present study aimed to evaluate the cardioprotective role of polyherbal extract on isoproterenol induced myocardial infarction in Wistar albino rat model.

Methodology: The rats were divided into eight groups each having six animals. Treatment I served as control, Treatment II rats were administered isoproterenol, Treatment III and IV were pretreated with polyherbal extract and received a subcutaneous injection of isoproterenol, Treatment $\mathrm{V}$ and $\mathrm{VI}$ were pretreated orally with propranolol and received a subcutaneous injection of isoproterenol, Treatment VII and VIII received polyherbal extract for 30 days. After cervical dislocation, the heart tissues were removed and studied for TCA cycle and respiratory chain enzymes along with histopathological observation.

Results: Isoproterenol induction exhibited significant $(p<0.05)$ reduction in the enzyme activities of mitochondrial TCA cycle. However, there was a significant $(p<0.05)$ increase in polyherbal treated rats of heart tissue homogenate. The effect of oral administration of polyherbal crude extract at $500 \mathrm{mg} \mathrm{g}^{-1} \mathrm{~b}$.wt. was found to have more effect than $250 \mathrm{mg} \mathrm{g}^{-1} \mathrm{~b}$.wt. Similarly, the standard drug propranolol $20 \mathrm{mg} \mathrm{g}^{-1} \mathrm{~b}$.wt. treated rats also exerted an effective impact. The histological sections prepared from isoproterenol hydrochloride treatment alone exhibited various degrees of focal lesions in several sections, consisting of staining and fragmentation of muscle fibers with confluent retrogressive lesions. Animals treated with polyherbal crude extract showed significant improvement in ISO-induced alterations such as vacuolar modifications, edema, capillary dilatation and leukocyte infiltration compared to ISOadministered group.

Interpretation: Polyherbal crude extract exhibited s y n e r g is t i c cardioprotective action which was revealed by improving the TCA cycle enzyme and protective effect on myocardium when compared to standard drug propranolol.

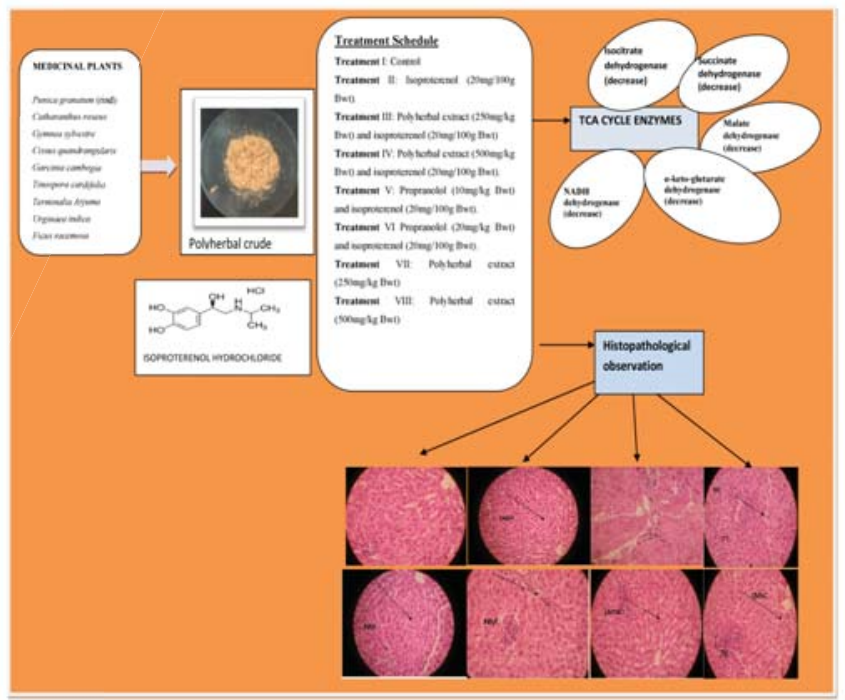




\section{Introduction}

Cardiovascular disease remains one of leading cause of death in several developing countries like India. The practice of using herbal medicines has been increasing over the past few decades to cure some of the disorders (Huang, 2010). Epidemiologists in India and International agencies such as World Health Organization have been creating awareness on the rapidly rising burden of cardiovascular disease for the past 15 years. The recorded occurrence of coronary heart disease in adult has consistently risen up to four folds in last 40 years. The same has doubled over the past 30 years even in rural areas. It is estimated that by 2020, cardiovascular disease will be the largest cause of disability and death in India (Reddy, 2007; Upaganlawar et al., 2011). Myocardial infarction or acute myocardial infarction is a medical term for cardiac attack. It occurs when blood stops flowing properly to all parts of the heart and insufficient supply of oxygen. Usually, coronary arteries that supply blood to the heart develops a blockage due to an improper production of white blood cells, cholesterol and fat in the system (Farvin et al., 2009; Valensi, 2014).

Most of the adenosine triphosphate generated by mitochondria is used as a source of chemical energy (Campbell et al., 2006). In addition to supplying cellular energy, mitochondria are involved in other tasks such as molecular signaling, cellular differentiation, cell death, regulation of cell cycle and cell growth (Bride et al., 2006). Mitochondria are generally considered as origin, but also as a target for reactive oxygen species (Batandier, 2002). They are continuously exposed to a flux of reactive oxygen species, produced either by respiratory complexes or other sources such as microsomal oxygenases and extracellular inflammatory responses (Cadenas, 2004).

Isoproterenol (1-[3,4 dihydroxyphenyl]-2-isopropyl amino ethanol hydrochloride) is a synthetic catecholamine and $\beta$ adrenergic agonist, which causes severe stress in the myocardium resulting in infarction, like necrosis of heart muscles (Mohanty et al., 2004). During this reaction, highly toxic oxygen free radicals are generated which are deterimental to extracellular and intracellular enzymes, proteins and other biomolecules. Furthermore, free radicals initiate peroxidation of membrane- bound polyunsaturated fatty acids leading to both functional and structural myocardial injury (Nikolaidis et al., 2002). Free radicals generated by isoproterenol alters membrane integrity and permeability in mitochondria. These alterations modified mitochondrial membrane structure and function by inactivating TCA cycle enzymes and altering mitochondrial respiration.

Current medical therapies for myocardial infarction aim at suppressing neurohormonal activation and treating fluid volume overload and hemodynamic symptoms (Ramadoss et al., 2012). this emphasises experiment based empirical knowledge coupled with elucidation of the exact chemical components present in the plants responsible for therapeutic action can provide a scientific basis to the herbal drugs and increase their acceptability. Such scientifically proven data will project herbal medicine in a proper perspective, and therefore may help to sustain the global market (Poongothai et al., 2002). Polyherbal formulations are known be highly effective against a vast number of diseases. The therapeutic effect of herbal medicines is apparent due to the presence of different phytoconstituents and the effects are further potentiated when compatible herbals are scientifically formulated together (Little, 2009; Mathew, 2011). Due to the fact that polyherbal formulations are a natural product, they are relatively cost effective, eco-friendly and easily accessible than allopathic drugs (Inamdar, 2008). With the above mentioned pharmacological evidence, nine medicinal plants such as Punica granatum (rind), Catharanthus roseus, Gymnema sylvestre, Cissus quadrangularis, Garcinia cambogia, Tinospora cordifolia, Terminalia arjuna, Urginea indica and Ficus racemose with antioxidant, hypocholesterolemic, free radical scavenging and cardiotonic activity were chosen for the present investigation.

In light of the above, the objective of the present study was to evaluate polyherbal extract of selected plants on mitochondrial function in isoproterenol-induced myocardial infarction in rats.

\section{Materials and Methods}

Preparation of polyherbal extract : One gram of polyherbal formulation consisted of equal amount of Punica granatum (rind), Catharanthus roseus (leaves), Gymnema sylvestre (leaves), Cissus quadrangularis (leaves and stem), Garcinia cambogia (fruit), Tinospora cordifolia (dimber), Terminalia arjuna (bark), Urginea indica (bulb) and Ficus racemosa (fruit and leaves). Ten grams of dried powder of each plant was added to cold macerated ethanolic solvent with occasional stirring for 3 days. After 3 days, the suspension was filtered through a fine muslin cloth and the filtrate was evaporated to dryness at low temperature $\left(<400^{\circ} \mathrm{C}\right)$ under reduced pressure in a rotary evaporator. The yield of crude extract was named as polyherbal extract, which was found to be $25 \mathrm{~g}$ and was stored in an air-tight desiccator's and used for further analysis.

\section{Experimental protocol}

Selection of animals: Male albino rats of Wistar strain weighing about 130-150 g, obtained from the Animal Breeding Station, Thrissur, Kerala, India were used for the study. The animals were few standard pellets under standard laboratory conditions: humidity $(40-70 \%)$, temperature $\left(25 \pm 20^{\circ} \mathrm{C}\right)$ and light ( $12 \mathrm{hrs}$ light/ dark). The protocol of the study was approved (KMCERT/PhD/ 15/2015-2016) by the Institutional Animal Ethic Committee (IAEC) of Kovai Medical Centre Research and Education Trust.

A total of forty eight animals were used and divided into eight treatments containing six animals each. Treatment I: served 
as control; Treatment II : rats were administered Isoproterenol (20 $\mathrm{mg} \mathrm{g}^{-1}$ b.wt.) subcutaneously twice at an interval of $24 \mathrm{hrs}$ dissolved in normal saline; Treatment III and Treatment IV: rats were pretreated with polyherbal extract ( 250 and $500 \mathrm{mg} \mathrm{g}^{-1} \mathrm{~b}$.wt.) for a period of 30 days and isoproterenol (20 mg g $\mathrm{mg}^{-1}$ b.wt.) subcutaneously twice at an interval of $24 \mathrm{hrs}$ at the end of treatment period on 29th and 30th day; Treatment $V$ and Treatment VI: rats were pretreated with Propranolol (10 and 20 $\mathrm{mg} \mathrm{g}^{-1}$ b.wt.) for a period of 30 days and isoproterenol $\left(20 \mathrm{mg} \mathrm{g}^{-1}\right.$ b.wt.) subcutaneously twice at an interval of $24 \mathrm{hrs}$ at the end of treatment period on 29th and 30th day; Treatment VII and Treatment VIII: rats were treated with polyherbal extract (250 and $500 \mathrm{mg} \mathrm{g}^{-1}$ b.wt.) for a period of 30 days.

After the last treatment, all the rats were sacrificed by cervical dislocation. Heart tissue was excised immediately and rinsed in ice chilled normal saline. One gram of heart tissue was taken and homogenized with $0.1 \mathrm{M}$ cold buffer $(\mathrm{pH} 7.4)$ in a potter homogenizer connected with a Teflon plunger at 600 revolutions per $3 \mathrm{~min}$. The homogenate was considered for various biochemical assays.

\section{Biochemical analysis}

Enzymes of TCA cycle: The following enzymes of TCA cycle were estimated in the present study: Isocitrate dehydrogenase (ICDH) activity were estimated by the method of King (1965); Succinate dehydrogenase (SDH) was estimated by the method of Slater and Bonner (1952); Malate dehydrogenase (MDH) was estimated by the method of Mehler (1948); a- keto-glutarate DHase was estimated by the method of Reed and Mukerjee (1969) and NADH dehydrogenase was estimated by the method of Minakami (1962).

Histopathological observation: Animals were sacrificed at the end of the treatment period; hearts were removed, washed immediately with saline and then fixed in 10\% buffered formalin. The hearts stored in $10 \%$ buffered formalin were embedded in paraffin, sections of $5 \mathrm{~mm}$ were cut and stained with hematoxylin and eosin. These sections were then studied under a light microscope for histopathological changes and photomicrographs were taken at $100 \mathrm{X}$ magnification (Dunn, 1974).

Statistical analysis : Results were expressed as mean \pm SD. The data were statistically analyzed by one-way analysis of variance (ANOVA) followed by Duncan's multiple range test (DMRT), using a statistical package program (SPSS 10.0 for windows) taking $\mathrm{P}<0.05$ as significant (Steel and Torrie, 1960).

\section{Results and Discussion}

As shown in Table 1, the isoproterenol- induced myocardial rats of Treatment II showed significant $(p<0.05)$ decrease in isocitrate dehydrogenase, malate dehydrogenase, succinate dehydrogenase, NADH dehydrogenase, a-
Ketoglutarate dehydrogenase compared to control rats in Treatment I. Except for NADH, all the TCA cycle enzymes were located in the outer membrane of mitochondria and could be pretentious by excessive production of free radicals by isoproterenol (Prabu et al., 2006; Brindha and Rajasekapandiyan, 2015). Inhibition of these enzymes by ROS may affect the oxidation of mitochondrial substrate, resulting in reduced oxidation of substrates, reduced rate of transfer of reducing equivalents to molecular oxygen and depletion of cellular energy (Capetenaki, 2005).

Succinate dehydrogenase is an integral membrane protein which is tightly embedded in the inner membrane and directly linked to the electron transport, transferring electrons to the respiratory chain (Singh et al., 2005). This serves as a metabolic control mechanism in TCA cycle and contains many cysteine-rich sulfur clusters and can be inhibited by agents that modify sulfhydryl treatments. Isoproterenol administration has been found to alter protein-bound sulfhydryl treatments, and hence might have resulted in inactivation of the enzyme (Kumar and Anandan, 2005).

NADH dehydrogenase located in the inner mitochondrial membrane is involved in the synthesis of ATP, which requires cardiolipin. This could result due to induced free radical, destabilization of mitochondrial membrane or due to enhanced phospholipid degradation and nonavailability of cardiolipin for its functional activity (Padma and Devi, 2005; Ragavendran et al., 2005; Suchalatha et al., 2007).

An increase in proteolytic activity during isoproterenol induction is also responsible for decrease in MDH activity (Paneerselvam and Govindaswamy, 2002). A decreased MDH activity in Treatment II might be due to increased production of free radicals in mitochondrial cells and decrease in oxygen consumption (Sima, 2003).

Isocitrate dehydrogenase (ICDH) catalyzes oxidative decarboxylation of isocitrate to a-ketoglutarate and requires either NAD ${ }^{+}$or $\mathrm{NADP}^{+}$to produce NADH and NADPH (Palsamy and Subramanian, 2009). Therefore, ICDH acts as an antioxidant in oxidative stress condition. It is involved in the supply of NADPH required for GSH production against mitochondrial and cytosolic oxidative damage (Narendhirakannan et al., 2006; Jo et al., 2001). Hence, reduced activity of ICDH results in the perturbation of balance between oxidants and antioxidants subsequently, leading to a pro-oxidant condition. The activity of ICDH can be down regulated by glycation of ICDH. Reactive oxygen species contribute to inactivation of ICDH by glycation mechanism (Lee et al., 2002; Kil et al., 2004).

Free radical mediated damages occur in biological membranes and subcellular organelles, where PUFAs are rich. Activation of LPO in mitochondria corresponds with change in 
lipid composition which includes a down-regulation in the level of total and readily oxidizable lipid, cardiolipin (Lee and Chou, 2002). These results are in line with the previous study of lhab et al., (2013), who reported diminished activities of TCA cycle enzymes in doxorubicin-induced rats along with nicorandil.

Pretreatment with hydroethanolic polyherbal crude extract of Treatment III and Treatment IV exerted a significant $(p<0.05)$ elevation in isocitrate dehydrogenase, malate dehydrogenase, succinate dehydrogenase, NADH dehydrogenase and a-Ketoglutarate dehydrogenase. This protection against isoproterenol inevitably suggests that the phytochemicals are potent in maintaining the mitochondrial membrane integrity (Zhou et al., 2007). Ragavan and Monisha (2016) proved that polyherbal crude extract was found to counteract reactive oxygen species and increased antioxidant defense status in experimental animals (Ragavan and Monisha, 2016). Medicinal plants tend to increase GSH content and protects reduced glutathione from free radical attack, which helps to maintain the activity of enzymes like dehydrogenases that require or possess sulfhydryl treatments at the active site (HellerStilb et al., 2001). Since TCA cycle enzymes are located in the mitochondrial inner membrane and matrix region, the ability of polyherbal crude extract to maintain the mitochondrial membrane intact offers an important protective mechanism against isoproterenol-induced alterations in the mitochondrial
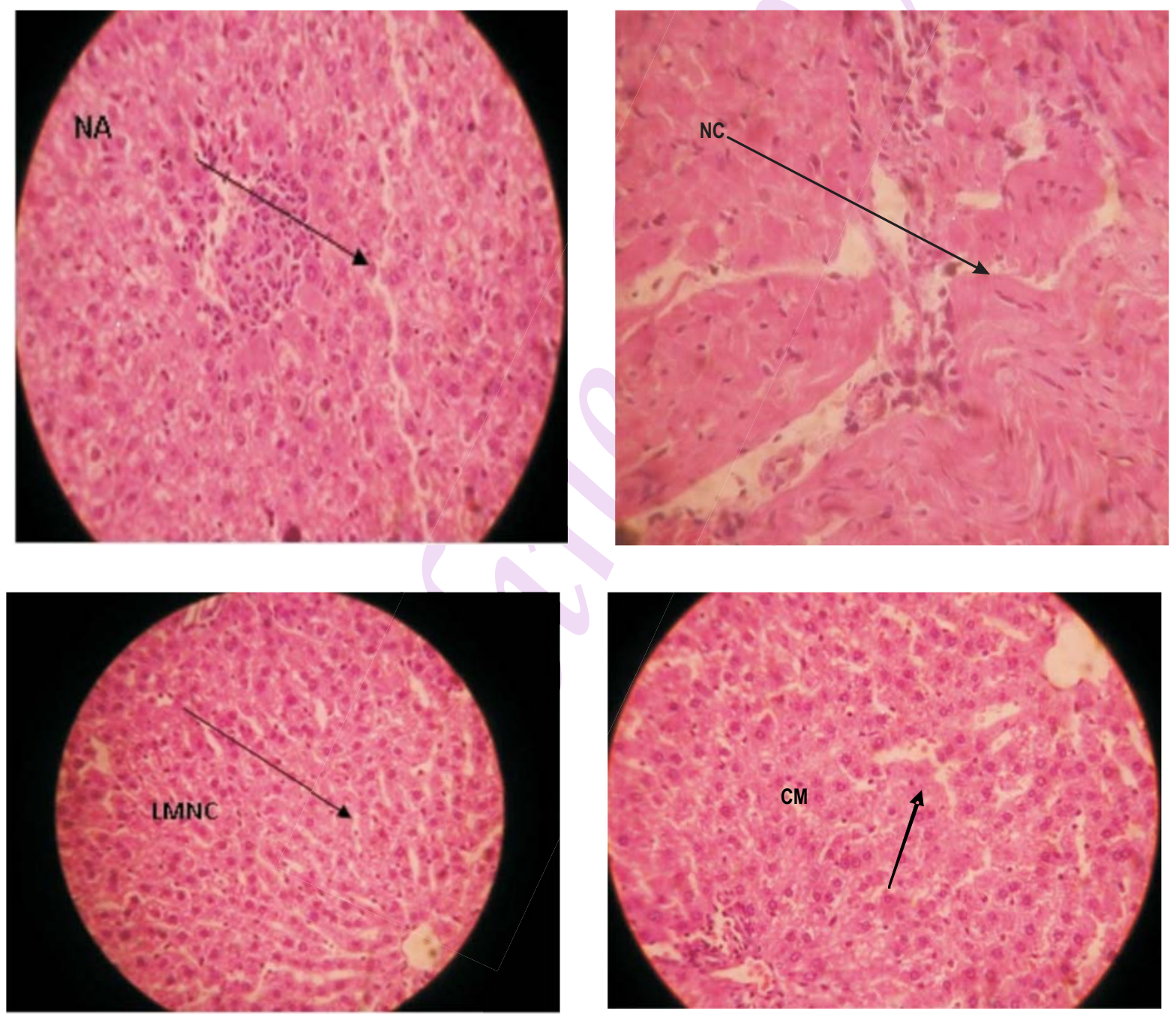

Fig. 1 (a-d) : Histological examination of heart tissue sections in control and experimental animals (a) normal control heart showing normal myecarduim fibsels; (b) showing necrosis (NC) of myofibrils and edema through penetration of inflammatory cells (IC), normal extravasation of RBC; (c) showing lesser myocardial necrosis (LMNC) and edema; (d) showing myocardial necrosis and edema with conical myocardium (CM) and showed healthy, (Hematoxyline and Eosin 100x) 
membrane. The polyherbal extract contains enormous level of phytoconstituents which are capable of producing changes in the metabolic pathways. Flavonoids, especially quercitin and phytic acid have free radical scavenging property (Ragavan and Monisha, 2016). It consists of calcium, magnesium and potassium that inhibits phospholipid degradation in the biological membranes, thereby maintaining the level of cardiolipin in the membrane, and shoots up ATP generation and TCA cycle enzymes (Brindha and Rajasekapandiyan, 2015). Similar results were reported by Kumar et al. (2015), who studied the action of Centella asiatica against isoproterenol induced Ml in rats.

No significant $(p<0.05)$ changes in Treatment $V$ were recorded when compared with Treatment III and IV. The polyherbal crude extract and standard drug propranolol produced
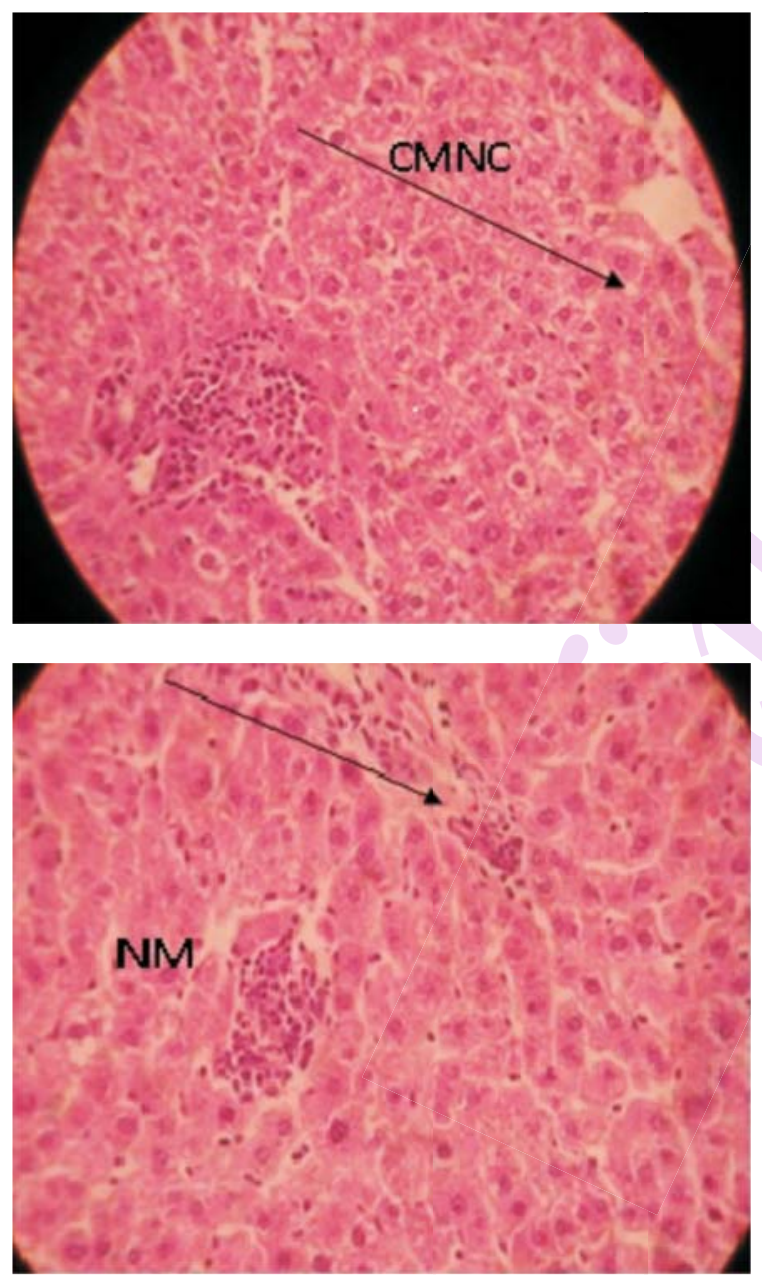

similar effect on the TCA cycle enzymes due to the presence of nine medicinal plants of which, Terminalia arjuna, Tinospora cardifolia and Urginea indica are well known for their antioxidant and cardioprotective activity which prevents membrane damage and leakage of enzymes (Sharma and Ekka, 2016; Shrivastava et al., 2014; Shukla etal., 2010).

The result exhibited a protective role of polyherbal crude extract that acted as a free radical and ROS scavengers in the electron transport chain of mitochondria. This indicates that deranged energy metabolism in isoproterenol induced $\mathrm{MI}$ was restored and favorable retainment of mitochondrial TCA cycle enzymes. The major compounds present in the polyherbal crude extract were hexadecanoic acid, octadecenoic acid, pentadecanoic acid, $1 \mathrm{H}$ - pyrrolo (2,3c)pyridine-3-propanoic
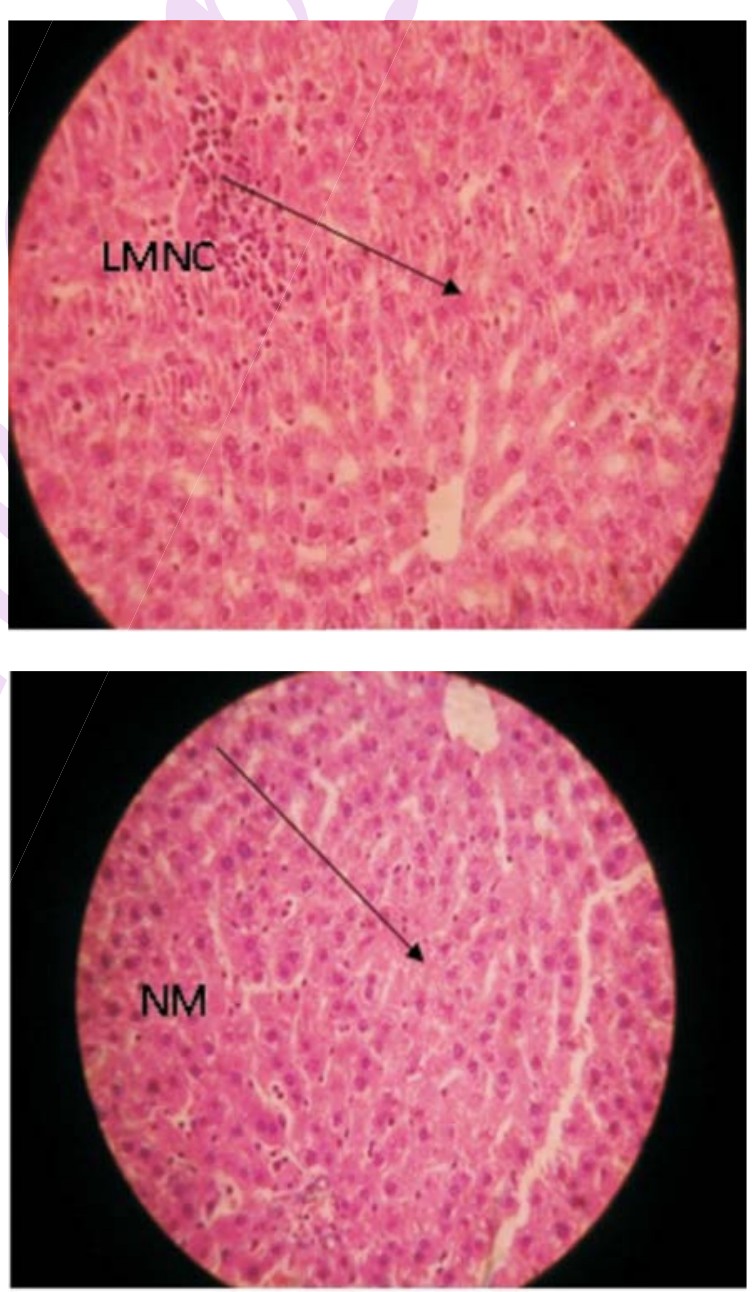

Fig. 1 (e-h) : Histological examination of heart tissue sections in control and experimental animals (e) showing decreased degree of necrosis and less inflammation cells along with conical myocardial necrosis (CMNC) and edema; (f) showing necrosis (NC) of myofibrils and edema through penetration of inflammatory cells (IC), normal extravasation of RBC; $(\mathrm{g})$ showing less myocardial necrosis and mild tissue degeneration; (h) showing normal myocardium fibres 
Table 1 : Effect of polyherbal extract on TCA cycle enzymes of winstar rats

\begin{tabular}{llllll}
\hline Treatments & $\begin{array}{l}\text { Isocitratede } \\
\text { hydrogenase }\end{array}$ & $\begin{array}{l}\text { Malatede } \\
\text { hydrogenase }\end{array}$ & $\begin{array}{l}\square \text {-ketoglutarate } \\
\text { dehydrogenase }\end{array}$ & $\begin{array}{l}\text { Succinatede } \\
\text { hydrogenase }\end{array}$ & NADH-DHase \\
\hline Treatment I & $647.19 \pm 4.56^{\mathrm{a}}$ & $318.62 \pm 0.23^{\mathrm{a}}$ & $107.37 \pm 0.69^{\mathrm{a}}$ & $235.90 \pm 1.45^{\mathrm{a}}$ & $160.05 \pm 4.08^{\mathrm{a}}$ \\
Treatment II & $438.86 \pm 14.17^{\mathrm{b}}$ & $190.60 \pm 0.24^{\mathrm{b}}$ & $69.40 \pm 0.30^{\mathrm{b}}$ & $125.02 \pm 1.23^{\mathrm{b}}$ & $83.87 \pm 1.35^{\mathrm{b}}$ \\
Treatment III & $480.84 \pm 12.19^{\mathrm{c}}$ & $285.40 \pm 7.50^{\mathrm{c}}$ & $70.80 \pm 6.16^{\mathrm{c}}$ & $105.10 \pm 3.76^{\mathrm{d}}$ & $124.93 \pm 2.12^{\mathrm{c}}$ \\
Treatment IV & $666.63 \pm 11.73^{\mathrm{d}}$ & $297.25 \pm 5.37^{\mathrm{d}}$ & $85.58 \pm 2.95^{\mathrm{d}}$ & $177.62 \pm 1.61^{\mathrm{c}}$ & $147.45 \pm 2.8^{\mathrm{d}}$ \\
TreatmentV & $480.50 \pm 11.27^{\mathrm{c}}$ & $285.90 \pm 3.77^{\mathrm{c}}$ & $70.27 \pm 4.28^{\mathrm{c}}$ & $105.82 \pm 3.11^{\mathrm{d}}$ & $124.78 \pm 2.15^{\mathrm{c}}$ \\
Treatment VI & $666.92 \pm 11.27^{\mathrm{d}}$ & $297.03 \pm 0.81^{\mathrm{d}}$ & $85.17 \pm 3.90^{\mathrm{d}}$ & $177.92 \pm 2.86^{\mathrm{c}}$ & $147.43 \pm 5.15^{\mathrm{d}}$ \\
Treatment VII & $647.89 \pm 13.92^{\mathrm{a}}$ & $318.75 \pm 0.55^{\mathrm{a}}$ & $107.14 \pm 2.74^{\mathrm{a}}$ & $235.67 \pm 3.52^{\mathrm{a}}$ & $160.20 \pm 4.03^{\mathrm{a}}$ \\
Treatment VIII & $647.85 \pm 12.02^{\mathrm{a}}$ & $318.72 \pm 0.70^{\mathrm{a}}$ & $107.08 \pm 3.49^{\mathrm{a}}$ & $235.40 \pm 3.23^{\mathrm{a}}$ & $160.12 \pm 3.00^{\mathrm{a}}$ \\
\hline
\end{tabular}

Values are mean \pm SD of six samples in each Treatment; ICDH- nmol of $\alpha$-keto-glutarate formed min $^{-1} \mathrm{mg}^{-1}$ of protein; MDH- $\mu$ mol of NADH oxidized $\mathrm{min}^{-1} \mathrm{mg}^{-1}$ of protein; $\alpha-\mathrm{k}-\mathrm{G}$ DHase -nmol of ferrocyanide formed $\mathrm{min}^{-1} \mathrm{mg}^{-1}$ of protein; $\mathrm{SDH}-\mu \mathrm{nmol}$ of succinate oxidised $\min ^{-1} \mathrm{mg}^{-1}$ of protein; NADH-

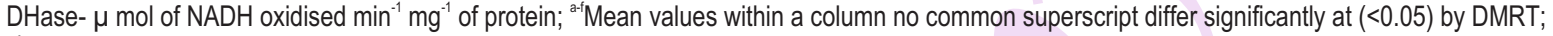
a-fMean values within a column of common superscript means non-significant

acid,5(4H)oxo-6,7, dihydro, 3 Butene-2-one,4(2,5, 6tetramethy1-2cyclohexen-1-yl),2(E)Heptenoicaci,4(s)-4[(tbutoxycarbonyl- (R)- Phenylalanyl-(s)-alanyl)amino)-6-methyl, Ethyl oleate, N-(4-Benzyloxy-Phenyl)-2 iodo-benzamide, 55'BiPhthalide, Dihydroergokryptine, 2(1H)- Napthalenone, 1dimethoxymethyl)- 3,4,5,6,7,8-hexahydro, 5-Methoxy carbonyltbercidin, Naphth(1,2-b)oxirene,1a,2,3,7b-tetrahydro, 1,3,12-Nonadecatriene, 2Methyl-E-7 hexadecene, 8 Hexadecenal, 14-methl (Z) present in medicinal plants. These compounds resemble the structure of flavonoids, glycosides and alkaloids, which are the major constituent of cardiovascular diseases.

The histopathological study of heart tissues of control rats (Treatment I) showed normal cell structure with normal myocardium. Rats injected with isoproterenol (Treatment II) showed necrosis of myofibrils and edema through penetration of inflammatory cells and extravasation of RBC. These characteristic changes were due to disruption of muscular damage of isoproterenol. Some of the earlier studies reported that ROS are responsible for the release of lysosomal enzymes in the cytosol, leading to further myocardial cellular injury during myocardial Infarction (Vimal and Devaki, 2004). Isoproterenol induction strongly increased lysosomal hydrolase activities inducing tissue damage as well as altering the fragility of lysosomal membrane of cardiomyocytes (Ahmed et al., 2004; Mukthamba and Srinivasan, 2015). The observation made in the present study is in confirmation with previous of studied by Kumar et al., (2007), where similar histological changes in heart tissues were reported in isoproterenol- induced myocardial infarction in rats (Anoiske and Cajetan, 2015; Muruganandan et al., 2002; Peabhu et al., 2006; Kumar et al., 2007).

A section of heart tissues in rats (Treatment III and IV) showed mild inflammation and focal myocardial necrosis (at one place) in comparison with Treatment II. Polyherbal crude extract reversed the changes in muscle cells and focal cardiac fibers with a well prevented normal morphology of cardiac muscle with minimal lesions. These changes were found due to rich bioactive constituents such as flavonoids, tannins, alkaloids and glycosides and antioxidant profile. Similar histological effects of Bombyx mori and Rhododendron arboreum was observed in isoproterenol-induced myocardial rats (Mahmood et al., 2015; Mudagal et al., 2011).

The heart tissues of isoproterenol-induced rats in Treatment $\mathrm{V}$ and Treatment $\mathrm{VI}$ showed lesser myocardial necrosis and edema along with mild inflammation than Treatment III and IV. These histological changes were seen due to the inhibitory effect of propranolol, which is $\beta$ - blockers. (Neri et al., 2015). Propranolol is a lipophilic $\beta$-blocker in nature $\beta$-adrenergic blockers are being useful adjuvants in the management of myocardial necrosis. Senthil et al. (2007) suggested that the therapeutic effects of propranolol in combination with other specific agents have shown similar histological recovery of heart cells. Likewise, Panda (2015) studied the effect of Moringa oleiferalam in isoproterenol induced myocardial infarction in rats. Rats treated with $20 \mathrm{mg} \mathrm{g}^{-1}$ b.wt. of propranolol showed mild inflammation and necrosis when compared with rats treated with $10 \mathrm{mg} \mathrm{g}^{-1}$ b.wt. of propranolol.

Asection of inflammatory cells in rats (Treatment VII and VIII) showed normal myocardium, no inflammation, and no focal myocardial necrosis in the focal area. However, the polyherbal extract did not alter the structure of cardiac cell. The effect of oral dose of $500 \mathrm{mg} \mathrm{g}^{-1} \mathrm{~b}$.wt. was more efficacious than $250 \mathrm{mg} \mathrm{g}$ ${ }^{1}$ b.wt.

Polyherbal crude extract possess significant therapeutic and beneficial effects in the protection of heart against isoproterenol induced myocardial infarction, possibly through inhibiting lipid peroxidation and cytokine level or cardiolipin. 


\section{References}

Abdel-Raheem, I.T., A. Taye and M.M. Abouzied: Cardioprotective effects if Nicorandil, a mitochondrial potassium channel opener against Doxorubicin-induced cardiotoxicity in Rats. Basic and clinical Phrmacology, 113, 158-66 (2013).

Ahmed, K.K., A.C. Rana and V.K. Dixit: Effect of Calotropis procera latex on isoproterenol induced myocardial infarction in albino rats. Phytomedicine, 2, 327-330 (2004).

Anosike, C.A. and I.C. Cajetan: Effect of Theobroma cacao polyphenol on isoproterenol-Induced myocardial infarction in Wistar rats. $\mathrm{J}$. App. Pharm. Sci., 5, 76-83 (2015).

Batandier, C., E. Fontaine, C. Keriel and X.M. Leverve: Determination of mitochondrial reactive oxygen species: methodological aspects. $J$ Cell. Mol. Med., 6,175-87(2002).

Bride, H.M., M. Neuspiel and S. Wasiak: Mitochondria: More than just a powerhouse. Curr. Biol., 16, 551-60 (2006).

Brindha and Rajasekapandiyan: Protective role of phytic acid on cardiac mitochondrial enzymes during isoproterenol-induced myocardial infarction in rats. Inter. Res. J. Pharma. Biosci., 2, 21-31(2015).

Cadenas, E.: Mitochondrial free radical production and cell signaling. Mol Asp. Med., 25, 17-26 (2004).

Campbell Neil, A., B. Williamson and J. Robin: Heyden Biology: Exploring Life. Boston, Pearson Prentice Hall, Massachusetts, 70 , 222-226 (2006).

Capetenaki, Y. and D. Cytoskeleton: A potential regulator of muscle mitochondria behavior and function. Tren. Cardiov. Medi., 12, 339-348 (2005).

Dunn, W.L.: Handbook of histopathological and histochemical techniques. $3^{\text {rd }}$ Edn., Redwood, Bun, Ltd., Trowbridge and Esher (1974).

Farvin, K.H.S., R. Anandan, S.H.S. Kumar, K.S. Shiny, S. Mathew, T.V. Sankar and P.G.V. Nair: Cardioprotective effect of squalene on lipid profile in isoprenaline-induced myocardial infarction in rats. J. Med. Food, 9, 531-6 (2009).

Gurujeyalakshmi, G., Y. Wang and S.N. Giri: Suppression of bleomycininduced nitric oxide production in mice by taurine and niacin. Nitric Oxide, 4, 399-411(2000).

Heller-Stilb, B., C. van Roeyen, K. Rascher, H.G. Hartwig, A. Huth, M.W. Seeliger, U. Warskulat and D. Haussinger: Disruption of taurine transporter gene (taut)leads to retinal degeneration in mice. FASEB J.Feb, 16, 223-231 (2002).

Huang, C., X. Zhang, J.M. Ramil, S. Rikka, L. Kim, Y. Lee, N.A. Gude, P.A. Thistlethwaite and M.A. Sussman: Juvenile exposure to anthracyclines impairs cardiac progenitor cell function and vascularization resulting in greater susceptibility to stress-induced myocardial injury in adult mice. Circulation, 121, 675-83 (2010).

Ithayarasi, A.P. and C.S.S. Devi: Effect of alpha tocopherol on lipid peroxidation in isoproterenol-induced myocardial infarction in rats. Indian. J. Physiol. Phararmacol., 41, 369-376 (1997).

Inamdar, N., S. Edalat, V.B. Kotwal and S. Pawar: Herbal drugs in milieu of modern drugs. Int. J. Green Pharm., 2, 2-8 (2008).

Ihab, T. A.R., A. Taye and M. M. Abouzied: Cardioprotective effects of Nicorandil, a mitochondrial potassium channel opener against Doxorubicin- induced cardiotoxicity in rats. Basic Clini. Pharmacol. Toxicol., 113, 158-66 (2013).

Jo, S.H., M.K. Son, H.J. Koh, S.M. Lee, I.H. Song, Y.O. Kim, Y.S. Lee, K.S. Jeong, W.B. Kim, J.W. Park, B.J. Song and T.L. Huh: Control of mitochondrial redox balance and cellular defense against oxidative damage by mitochondrial NADP+ -dependent isocitrate dehydrogenase. J. Biol. Chem., 276, 16168-16176 (2001).

Kil, I.S., J.H. Lee, A.H. Shin and J.W. Park: Glycation induced inactivation of NADP+ -dependent isocitrate dehydrogenase: Implications for diabetes and aging. Free Radic. Biol. Med., 37, 1765-1778 (2004).

King, J.: Lactate dehydrogenase in practical clinical enzymology (Ed.: D. Van). Nostrand Co, London; pp. 83-93(1965).

Kosuge, M., K. Kimura, T. Ishikawa, T. Ebina, K. Hibi, K. Tsukahara, M. Kanna, N. Iwahashi, J. Okuda, N. Nozawa, H. Ozaki, H. Yano, T. Nakati, I. Kusama and S. Umemura: Differences between men and women in terms of clinical features of ST-segment elevation acute myocardial infarction. Circulation J., 70, 222-226 (2006).

Kumar, S.H.S. and R. Anandan: Biochemical studies on the cardioprotective effect of glutamine on tissue antioxidant defense system in isoprenaline-induced myocadial infarction in rats. J. Clin. Biochem. Nutr., 40, 49-55 (2005).

Kumar, V., V. Babu, K. Nagarajan, L. Machawal and U. Bajaj: Protective effects of Centella asiatica against isoproterenol-induced myocardial infarction in rats: Biochemical, mitochondrial and histological findings. J. Phyto. Pharmacol., 4, 80-86 (2015).

Lee, S.M., H.J. Koh, D.C. Park, B.J. Song, T.L. Huh and J.W. Park: Cytosolic NADP+ -dependent isocitrate dehydrogenase status modulates oxidative damage to cells. Free Radic. Biol. Med., 32, 1185-1196 (2002)

Little, C.V.: Simply because it works better: Exploring motives for the use of medical herbalism in contemporary U.K. health care. Complement. Ther. Med., 17, 300-8 (2009).

Mathew, L. and S. Babu: Phytotherapy in India: Transition of tradition to technology. Curr Bot., 2, 17-22 (2011).

Mehler, A.H., A. Konberg, S. Criscolin and S. Ochon: The enzymatic mechanism of oxidation-reductions between malate or isocitrate or pyruvate. J. Biol. Chem., 174, 961-977 (1948).

Minakami, S., R.L. Ringler and J.P. Singer: Studies on the respiratory chain linked dihydrophosphopyridine nucleotide dehydrogenase I, assay of the enzyme in particulate and in soluble preparations. J. Biol. Chem., 237, 569-576(1962).

Mohanty, I., D.S. Arya, A. Dinda, K.K. Talwar, S. Joshi and S.K. Gupta: Mechanism of cardioprotective effect of Withania somnifera in experimental induced myocardial infarction. Basic Clini. Pharmacol. Toxicol., 94,184-190 (2004).

Mudagal, P.M., S. Karia and D. Goli: Preventive effect of Rhododendron arboreum on cardiac markers, lipid peroxides and antioxidants in normal and isoproterenol-induced myocardial necrosis in rats. Afr. J. Pharmarmacol., 5, 755-763(2011).

Muruganandan, S., S. Gupta, M. Kataria, J. Lal and P.K. Gupta: Mangiferin protects the streptozotocin-induced oxidative damage to cardiac and renal tissues in rats. Toxicol., 176, 165-73(2002).

Murugesan, M., M. Ragunath, S. Nadanasabapathy, R. Revathi and V. Manju: Protective role of fenugreek on isoproterenol induced myocardial infarction in rats. Inter. Res. J. Phar., 3, 211-6(2012).

Narendhirakannan, R.T., S. Subramanian and M. Kandaswamy: Biochemical evaluation of antidiabetogenic properties of some commonly used Indian plants on Streptozotocin-induced diabetes in experimental rats. Clin. Exper. Pharmacol. Physiol., 33, 1150$1157(2006)$

Nayan, G.P., K.G. Patel, K.V. Patel and T.R. Gandhi: Myocardial scavenging effect of Premna mucronata Roxb (Verbenaceae) on isoproterenol induced myocardial necrosis in rats. Der Pharmacia Letter, 7, 137-147(2015). 
Neri, M., V. Fineschi, M. di Paolo, C. Pomara, I. Riezzo, E. Turillazzi and D. Cerretani: Cardiac oxidative stress and inflammatory cytokines response after myocardial infarction. Curr. Vasc. Pharmacol., 13, 26-36 (2015).

Nikolaidis, L.A., T. Hentosz, A. Doverspike, R. Huerbin, C. Stolarski, Y. Shen and R.P. Shannon: Catecholamine stimulation is associated with impaired myocardial $\mathrm{O}_{2}$ utilization in heart failure. Cardiov. Res., 53, 392-404 (2002).

Padma, V.V. and C.S. Devi: Effect of fish oil on mitochondrial respiration in isoproterenol induced myocardial infarction in rats. Indian J. Exp. Biol., 40, 268-272 (2005).

Palsamy, P. and S. Subramanian: Modulatory effects of resveratrol on attenuating the key enzymes activities of carbohydrate metabolism in streptozotocin- nicotinamide-induced diabetic rats. Chemico-Biol. Interac., 179, 356-362 (2009).

Panneerselvam, S. and S.S. Govindaswamy: Effect of sodium molybdate on carbohydrate metabolizing enzymes in alloxaninduced diabetic rats. J. Nutr. Biochem., 13, 21-26 (2002).

Poongothai, S., K. Karkuzhali, J. Sharadha, R. Deepa and V. Mohan: Evaluation of safety and efficacy of hyponidd, an Ayurvedic compound: A double blind, placebo controlled study in type 2 diabetic patients with secondary failure to oral drugs. Int. J. Diab. Dev. Ctries, 22, 19-27 (2008).

Prabhu, S., M. Jainu, K.E. Sabitha and S.C.S. Devi: Cardioprotective effect of mangiferin on isoproterenol induced myocardial infarction in rats. Indian J. Exp. Biol., 44, 209-15(2006).

Prabu, S., M. Jainu, K.E. Sabitha and C.S. Devi: Effect of mangiferin on mitochondrial energy production in experimentally induced myocardial infarction in rats. Vasc. Pharmacol., 44, 519-525 (2006).

Puttaswamy, M. and K. Srinivasan: Hypolipidemic influence of dietary fenugreek (Trigonella foenum-graecum) seeds and garlic (Allium sativum) in experimental myocardial infarction. Food Funct., 6 , 3117-3125(2015)

Ragavan, B. and M. Sudhakar: Cardioprotective potential of a hydroethanolic polyherbal crude extract on isoproterenol induced myocardial in wistar albino rats. Wor. J. Pharma. Res., 5, 10481069 (2016).

Ragavan, B. and M. Sudhakar: Antioxidant and phytochemical investigation of a polyherbal extract. Asian J. Pharma. Sci., 3, 1-11 (2015).

Raghavendran, H.R.B., A. Sakthivel and T. Devaki: Antioxidant effect of Sargassum polycystum (Phaeophyceae) against acetaminophen induced changes in hepaticmitochondrial enzymes during toxic hepatitis. Chemosphere, 61, 276-281 (2005).

Ramadoss, S., K. Kannan, K. Balamurugan, N.S. Jeganathan and R. Manavalan: Efficacy of cardioprotective effects in ethanolic extract of Sida rhombifolia Linn. On isoproterenol-induced myocardial infarction in albino rats. Res. J. Pharmac. Biol. Chem. Sci., 3, 488492 (2012).

Reddy, K.S.: Educational status and cardiovascular risk profile in
Indians. J. Am. Coll. Cardiol., 50, 1370-1372 (2007) .

Reed, L.J. and R.B. Mukherjee: a-ketoglutarate dehydrogenase complex from Escherichia coli. In: Methods in Enzymology (Ed.: J.M. Lowenstein). London, Academic Press, pp. 53-61 (1969).

Senthil, S., M. Sridevi and K.V. Pugalendi: Cardioprotective effect of oleanolic acid on isoproterenol-induced myocardial ischemia in Rats. Toxicologic Pathology, 35, 418-423, (2007).

Sharma, R. and A. Ekka: Diversity of medicinal plants in Pt. Ravishankar Shukla University, Raipur, Chhattisgarh, India. Euro. J. Pharma. Med. Res., 3, 383-397 (2016).

Shrivastava, A.K., A. Tikariha and S. Patra: Seasonal and floristic Biodiversity of weeds growing in Chunkatta and Bhilai area of Chhattisgarh, India. Int. J. Curr. Microbiol. App. Sci., 3, 318-326 (2014).

Shukla, A., S. Srivastava and A.K.S. Rawat: An ethnobotanical study of medicinal plants of Rewa district, Madhya Pradesh. Ind. J. Tradi. Know., 9, 191-202 (2012).

Sima, A.A.: C-peptide and diabetic neuropathy. Expert. Opin. Inves. Drugs, 12, 1471-1488 (2003).

Singh, R.J. : Glutathione: A marker and antioxidant for aging. J. Labor. Clin. Medi., 140, 380-381 (2005).

Slater, E.C.C. and W.D. Bonner: The effect of fluoride on succinic oxidase system. Biochem J., 52, 185-196 (1952).

Songjukta, C., M. Pujani and S.E. Haque: Combinational effect of resveratrol and atorvastatin on isoproterenol induced cardiac hypertrophy in rats. J. Pharm. Bioall. Sci., 7, 233-8 (2015).

Steel, R.G.D. and J.H. Torrie: Principles and procedures of statistics. McGraw-Hill Book Company, New York, p. 481 (1960).

Suchalatha, S., P. Srinivasan and C.S.S. Devi: Effect of T. chebula on mitochondrial alterations in experimental myocardial injury. Chem. Biol. Interact., 169, 145-53(2007).

Sunanda, P.: Butanolic fraction of moringa Oleifera lam (Moringaceace) attenuates isoproterenol- induced cardiac necrosis and oxidative stress in rats: An EPR study. EXClj., 14,64-74 (2015).

Tarique, M., H.H. Siddiqui, R. Dixit, P. Bagga and Md.S. Hussain: Protective effect of Bombyx mori $\mathrm{L}$ cocoon (Abresham) and its formulations against isoproterenol-induced cardiac damage. Trop. J. Pharm. Res., 14, 63-72 (2015).

Upaganlawar, A., H. Gandhi and R. Balaraman: Isoproterenol induced myocardial infarction: Protective role of natural products: J. Pharmacol Toxicol., 6, 1-17 (2011).

Valensi, P., L. Lorgis and Y. Cottin: Prevalence, incidence, predictive factors and prognosis of silent myocardial infarction: A review of the literature. Arch. Cardiov. Dise., 3, 178-88 (2014).

Vimal, V. and T. Devaki: Linear furanocoumarin protects rat myocardium against lipidperoxidation and membrane damage during experimental myocardial injury. Biomed. Pharmacother., 58, 393$400(2004)$.

Zhou, D., J. Xue, J. Chen, P. Morcillo, J.D. Lambert, K.P. White and G.C. Haddad: Experimental selection for Drosophila survival in extremely low $\mathrm{O}_{2}$ environment. PLOS ONE, 2, e490 (2007). 